\title{
Motivation and Identity: A Psychoanalytic Perspective on the Turn to Identity in Motivation Research
}

\section{By Michaela Driver, Ph.D.}

Western State Colorado University

School of Business

221 Borick Business Building

Gunnison, Colorado 81231

USA

Tel: $970-943-2673$

Fax: 970-943-7042

E-mail: mdriver@western.edu

\section{Biographical Note:}

Michaela researches alternative and psychoanalytic approaches to a wide range of organizational topics such as organizational identity and learning, emotions, trust, corporate social responsibility, identity work, creativity, embodied subjectivity and leadership. Journals in which Michaela's work has been published include Organization Studies, Human Relations, Academy of Management Learning \& Education, Organization, Management Learning, Journal of Organizational Change Management, Journal of Business Ethics, and Journal of Management Inquiry. She serves on several editorial boards including Organization Studies, Organization, Management Learning, and the Journal of Management Inquiry. 


\title{
Motivation and Identity: A Psychoanalytic Perspective on the Turn to Identity in Motivation Research
}

\begin{abstract}
Taking the recent turn to identity in motivation research as its starting point, the study attempts to move the field further beyond instrumentalizing and fractionalizing conceptions in which motivation is simply a question of pulling the right levers. Drawing on a psychoanalytic, particularly Lacanian, perspective and an analysis of 51 narratives shared by employees from a number of occupations, it develops a more fine-grained and complex understanding of how motivation functions in the context of identity work. Specifically, the study explores how motivation is invariably mapped onto internal struggles with unconscious subjectivity and desire. These may align individuals more with organizational ideals of the properly motivated employee but also create an empowering space in which they can work through work-related fantasies and find enjoyment on their own terms. The implications of this perspective are discussed.
\end{abstract}

Key Words: Motivation, Identity, Discourse, Psychoanalysis, Lacan

\section{Introduction}

Despite decades of research on motivation, attempts at integrating existing theories and the development of mega-theories (Locke and Latham, 2004; Steel and Koenig, 2006; Steers, Mowday and Shapiro, 2004), the question of how to motivate employees continues to be a concern (Barrick, et al., 2015). Attempts at answering it have involved the search for the right kind of systems or levers with which to properly stimulate and steer individuals' motivation "as the process by which behavior is energized, directed and sustained" (Leonard et al., 1999: 970). Yet, such levers remain elusive. Some seem to think that this is due to the shortcomings of 
existing theories and an inability to keep up with new developments in organizations. Classical motivation research, for instance, has been found to be inadequate "to address the new nature of work" (Ankli and Palliam, 2012: 8) and criticized for not providing sufficient theoretical purchase "to understand in what way people adapt in today's complex world of work" (Leonard, Beauvais and Scholl, 1999: 969).

To obtain such purchase, motivation research has taken a "turn to identity" (Alvesson, Ashcraft and Thomas, 2008: 6) entailing a "plethora of self-based theories" (Leonard et al., 1999: 973) in which motivation is explored in the context of how individuals develop desired selves in and through work. Specifically, it has been investigated how individuals story themselves in work contexts drawing on discursive resources offered by organizations through which the desire for self-validation and development is aligned with "an organizationally sanctioned self' (Sonenshein, Dutton, Grant, Spreitzer and Sutcliffe, 2013: 564). This perspective shares with prior approaches the idea that motivation is a question of finding the right levers to pull. The levers in this case are appropriate discursive resources that individuals can use to narratively construct their identities in ways that are aligned with organizational ideals as to the properly motivated and performing employee.

The present study takes this turn to identity in motivation research as a starting point but aims to shift the focus from finding effective levers to develop more complex insights. Particularly, it employs a psychoanalytic perspective (Lacan, 1988a;b) to explore how motivation discourse is drawn on as a resource for identity work in view of unconscious dynamics (Arnaud, 2007). While these have been acknowledged previously as important for understanding motivation (Kehr, 2004; Locke and Latham, 2004), the aim is to extend a 
Lacanian perspective, advanced but not widely developed, that considers unconscious desire as important for understanding motivation (Arnaud, 2007; Leather, 1983).

Drawing on this perspective, an analysis of empirical material consisting of narratives from over 50 employees from different organizations across a range of occupations highlights that motivation is often experienced as an internal struggle. Motivation discourse offers images of how to be an ideal motivated employee and find fulfilment through work. Individuals construct narratives in which they try to live up to these. But they find their constructions constantly unsettled in the face of lived experiences in which work is often instrumentalizing, unpleasant and meaningless. The latter increases the need to return work to its idealized status potentially further instrumentalizing individuals as they thrive to realize an organizationallysanctioned motivated self. However, it also offers opportunities for more empowering responses by which such difficulties can be articulated as a structural condition while individuals shape their identities in ways that are decoupled from the idealized motivated employee.

This perspective advances the idea that motivation scholarship and organizational practice can move beyond the search for the right levers that will properly motivate employees. Indeed, it suggests that there is very little to engineer when it comes to motivation. Rather whatever approach is adopted becomes a discursive resource that is absorbed in internal struggles with self and desire. While identity-focused approaches to motivation seem specifically engineered to be so absorbed with the result that employees are more easily manipulated (Hoedemaekers, 2009), the present study suggests that this is to miss a more fine-grained and complex understanding of how motivation functions at the interstice of identity work. Motivation discourse offers resources to construct a number of fantasies about how meaningful and enjoyable work can be and thereby fulfill underlying unconscious desires for feeling fulfilled and 
completed. However, such constructions are also always already unsettled by the inevitable experience of less fulfilling aspects of work and the impossibility of ever knowing what precisely is unconsciously desired (Lacan, 1988b: 211).

In short, the study elaborates a previously started Lacanian approach to motivation and deepens a narrative approach and methodology to explore it. In particular, it examines how any motivation discourse, whether focused on the self or otherwise, is not as totalizing as it might seem. It may or may not lead to desired organizational outcomes. Yet it is always productive in driving home the experience that a fulfilled and completed self cannot be realized through work. The more employees are asked to realize such a self, the more a space is created in which to not only construct but also work through such fantasies. The study contributes novel perspectives on motivation in which the continued conversation around motivation can be viewed as empowering. This perspective offers new avenues for examining motivation less as a system to be engineered and more as a resource for articulating how individuals can engage with and enjoy work on their own terms.

\section{Motivation}

The emphasis on finding the right levers and the performative aspects of motivation have long been criticized as being much too instrumental (Michaelson, 2005) addressing only situational and fractured conceptions of human subjectivity (Shamir, 1991). Most recently, therefore, motivation has been explored as a linguistic, subjective and socially-constructed phenomenon that can account for more complex understandings of subjectivity (Carlisle and Manning, 1994; Cullen, 1997; Johnson, Chang and Yang, 2010; Kanfer and Ackerman, 2004; Leonard, et al., 1999). In particular, there has been a focus on "self-based theories" (Leonard et 
al., 1999: 973) and the idea that individuals are motivated to the extent they feel work allows them to construct a desired identity (Shamir, 1991).

This has shifted the focus toward an integrative understanding of how "human beings [are] motivated to behave in ways that are consistent with existing self-perceptions" (Leonard et al., 1999: 973). Work is repositioned from the achievement of instrumental ends toward being a journey of life, learning and love (Ankli and Palliam, 2012: 9) with fulfillment at work tied to "expressing who one really is" (Ankli and Palliam, 2012: 9). From this perspective work is "a pervasive life domain and a salient source of meaning and self-definition for most individuals" (Dutton, Roberts and Bednar, 2010: 265). The increasing focus on identity (Dutton et al., 2010: 265) has also been accompanied by the adoption of narrative approaches (Sonenshein et al., 2013: 552) in which it can be explored how individuals use discursive resources to narrate the self and create meaning from ongoing experiences (Sonenshein et al., 2013: 553). With this view research focuses on how individuals "story who they are" (Dutton et al., 2010: 266) and how positive identity constructions "motivate individuals to take actions that promote positive outcomes in organizations" (Dutton et al., 2010: 267).

The turn to identity in motivation research has been welcomed by proponents not only as the response to the "growing realization that traditional models of motivation do not explain the diversity of behavior found in organizational settings" (Leonard et al., 1999: 969) but also as a way to highlight empowering ways in which individuals draw "from an array of [organizational discursive] resources to affirm their agency" (Sonenshein et al., 2013: 565). Critics argue that not only is this perspective not conducive to promote greater agency, it is more insidious in disempowering employees than traditional models of motivation. They argue that "managerial practices drawing on theories of motivation are... an attempt to link individual development to 
organizational performance in novel ways" (Hoedemaekers, 2009: 190). Practices intended to motivate employees by furnishing discursive resources for identity construction "promote a particular image of the individual and link it to organizational success by means of motivational aspects" (Hoedemaekers, 2009: 192). In exploring the reasons for this enhanced organizational control, some have highlighted the role of unconscious dynamics.

Drawing on theories by the French psychoanalyst, Jacques Lacan, Leather (1983) advances the idea that individuals are motivated by a desire to overcome a structural lack which is impossible to fulfill. It is in using this desire "to manage the labor process" (Hoedemaekers, 2009: 190) that organizational control has become so pervasive. As the self from this perspective suffers from an insurmountable internal void, organizational promises to provide a unified, complete and non-lacking selfhood are seductive (Hoedemaekers, 2009: 190). Therefore, even identity-based theories of motivation potentially instrumentalize employees by mapping, accidentally or intentionally, on to such vulnerabilities. They also reiterate the quest for the right motivational levers. Yet, they still do not seem adequate to accommodate the complexities of how motivation functions at the interstice of identity work.

\section{Motivation, Subjectivity and the Unconscious}

To better address such complexities, I now take up the project begun by Leather (1983) of introducing Lacanian theorizing to the study of motivation. Central to Lacanian conceptions of subjectivity is that human beings are fundamentally divided between who they consciously think they are and who they are as subjects of the unconscious (Lacan, 1977a;b; 1988a;b; 1991; 2001). On the one hand, individuals construct a conscious ego, as the "official discourse people pursue, identify with and present themselves with" (Arnaud and Vanheule, 2007: 361), which will be referred to here as self or identity. On the other hand, they are subjects as "an effect of the 
unconscious, not accepted by the ego" (Arnaud and Vanheule, 2007: 361) and subjected to the symbolic discourse of the "Other" (Lacan, 1977b: 214).

This order of the Other is the "world of the symbol" (Lacan, 1988b: 210). In this order we exist as social beings and articulate the self and its desires through ordinary speech (Lacan, 1977b: 245). Unfortunately, the self we so construct is fundamentally alienated (Lacan, 1988b: 210). There is always something missing from the symbolic. The signifiers we use are only the words of others. Consequently, what we articulate turns out to be a "desire for nothing" (Lacan, 1988b: 211) or what is unconsciously desired but impossible to name (Muller and Richardson, 1982: 373). As a result, what we consciously articulate in ordinary speech as who we are and what we want represents the efforts of the ego to "pretend" this is not so. Individuals become stuck in an imaginary order (Lacan, 1988b: 177) with only an alienated image of themselves.

While there is no permanent escape from the imaginary, there can be moments of “freedom" (Lacan, 1988a: 285). We can experience for ourselves how we are always caught between the imaginary illusion that we can overcome lack and the continuous experience of failing to do so (Lacan, 1977b: 218). At those moments, of which disruptions in speech like ambiguities, tangents, misconstructions, omissions and other rhetoric creations (Benvenuto and Kennedy, 1986: 13) are symptomatic, we experience the lack through which we obtain "a sense of self" (Lacan, 1988b: 223). That is, we are freed from the imaginary certainty that we know who we are and what we want. This is empowering and creative (Fink, 2004: 62) because we appreciate that unconscious desire is much too powerful to be extinguished by conscious articulations; and we can preserve desire for desire itself (Lacan, 1977b: 243). This also offers opportunities to work through the fantasy that perfect wish-fulfillment and bliss are possible. In 
doing so some enjoyment can be preserved by not constantly comparing expected, fantastic bliss to the apparently paltry satisfactions obtained (Fink, 2004: 157).

From this perspective, motivation discourse can be explored in the context of imaginary as well as symbolic responses to the problem that "work is structurally non-satisfying" (Arnaud and Vanheule, 2007: 363). On the imaginary side, motivation discourse is drawn on to construct an imaginary self. This self can know who it is and obtain what it wants in and through work. But it is continuously unsettled by the disappointments that such a stance makes inevitable as it is caught between the infinity of desire and the finitude of possible satisfactions work can offer (Arnaud and Vanheule, 2007: 363). On the symbolic side, instead of getting ever further enmeshed in this imaginary but futile pursuit, it becomes possible to work through imaginary relations and creatively transform narrative structures (Vanheule et al., 2003: 335).

This means that it becomes possible to work with the structural lack inherent in work (Arnaud and Vanheule, 2007: 365) and take different positions toward it (Vanheule et al., 2003: 336). In so doing, work and motivation can be narrated to account for a wider view of life (Vanheule et al., 2003: 334) as a process of becoming (Fink, 2004: 63). In this process it becomes possible to engage with motivation as a way of playing with not finding what one is looking for while enjoying the energy that the search continues to generate. This turns motivation discourse from a strictly organizational to a more personal resource to engage in important work for subjects (Arnaud, 2007) learning to move more freely between imaginary and symbolic stances to work and self.

\section{Empirical Material and Interpretation}

With these ideas in mind, the goal for this study is to explore how individuals in organizations subjectively construct motivation, not in the fragmented sense of traditional 
situational models, but in a more comprehensive fashion, in what might be referred to as general work motivation "to invest efforts in the work role - whatever the specific job one holds at a certain time" (Shamir, 1991: 414). In particular, the goal is to explore this as a sociallyconstructed and discursive means for expressing "self-concepts" (Shamir, 1991: 411) in the context of various unconscious dynamics (Kehr, 2004; Locke and Latham, 2004). In seeking to explore how such a perspective on motivation would resonate with the lived experiences of people working in organizations today, I went in search of individuals willing to share narratives about what they find motivating about their work.

Employing purposeful sampling (Glaser, 1978), I approached potential participants likely to have current work experience and who wished to share their reflections about what motivates them, however they defined that. Drawing on the rich, reflective potential of stories, especially with regard to unconscious dynamics, I sought to be a "fellow traveler" (Gabriel, 1995: 481) to interviewees signaling my interest in subjective meaning making (Gabriel, 1991: 871). Specifically, respondents were asked to share any thoughts or stories about what they might enjoy about their work, what might get them up in the morning to go to work, and what may be some typically good or not so good moments at work. In this fashion, a total of 51 employees were interviewed, 18 of which are female and 33 male. Interviews lasted from 30 to 45 minutes. To protect the anonymity of respondents all identifying information has been removed from the transcripts. Positions held by interviewees range widely from executive directors, senior managers and business owners to sales representatives, flight attendants, waiters, lab analysts, teachers, and parole officers. Industries in which interviewees work also range widely and include healthcare, hospitality, manufacturing, public services, insurance, retail, construction, transportation, media, education, financial services, military and high tech. 
Qualitative narrative inquiry (Ollerenshaw and Creswell, 2002; Sermijn, Devlieger and Loots, 2008) was employed, as a broad framework, to analyze the transcripts. This framework focuses particularly on the narrative construction of the self and is well suited to engage with texts from a Lacanian perspective (Parker, 2005; 2010). As a result, I followed methods employed in prior studies in which interview transcripts were examined specifically drawing on Lacanian ideas (e.g. Hoedemaekers and Keegan, 2010). These studies acknowledge that using ideas developed for clinical psychoanalytic practice, while needing some translation, could nonetheless be fruitfully adapted to organizational research (Parker, 2005: 168). I sought to engage with the interview transcripts not as a means for uncovering what narrators really meant but rather to explore how various signifiers were arranged in unique and interesting ways (Parker, 2005: 167). That is, I tried to replace "a sense of holistic closure...[with] a set of provoking questions" (Saville Young, 2014: 281). In this way, I was not reducing narratives to objectifying and generalizable truths (Parker, 2005: 165) but rather attempted to encircle and play with the texts to highlight what I thought were transformative moments in my readings of them (Saville Young, 2014: 288). These are necessarily mis-readings undertaken from the position of having to step out of the text to say something about it while always being situated in and through it (Saville Young, 2014: 283). While the purpose of this approach is to illustrate the complexities of motivation, it is important to appreciate that the analysis is only a snapshot of a process that intentionally lacks "completion" (Holmes, 2014: 782).

With this in mind, I followed a reflexive and iterative reading of the empirical material (Alvesson and Skoldberg, 2000) becoming more psychoanalytic in orientation (Parker, 2005; 2010). I first identified the content or themes in the narratives that enable some subject positions while precluding others (Saville Young, 2014: 283). Specifically, I examined how the discourse 
of motivation was drawn on by the narrators not necessarily in ways that were managerially sanctioned. My goal was to uncover how motivation discourse was drawn on by narrators in a way that made it relevant to them (Learmonth, 2009). Taking a more hermeneutic approach (Alvesson and Skoldberg, 2000), I then distilled key themes that seemed to be crucial to narrators in terms of what motivation meant to them and how it may be drawn on to do identity work. In view of the latter, I drew on more psychoanalytically-informed perspectives to examine the narratives as both imaginary and symbolic responses (Vanheule et al., 2003). Specifically, I examined the narratives as imaginary constructions of the self and then explored various tensions in the narratives (Saville Young, 2014: 283) surfacing the potential unsettling of the imaginary. I then examined whether there were also more symbolic responses in the narratives. Finally, I explored the narratives for moments where narrators may be working through the fantasy that work can render the self complete (Hoedemaekers, 2009: 190).

\section{Motivation and the Imaginary Self}

Based on this analysis, motivation emerges as a discourse that is drawn on not only to construct a positive identity (Dutton et al., 2010) but also an imaginary self. Narrators often define their motivation by describing how they see themselves as happy employees who love their work and obtain satisfaction from helping others. By referencing this construction of imaginary selves, I am not implying that the narrators are deluding themselves into thinking that work is as enjoyable or meaningful as they describe. Indeed, the entire approach adopted here is different from a Marxist-style critique (Arnaud, 2007: 1) in which reports of meaningful work and employee happiness may be dismissed as the claims of falsely-conscious and duped employees (Jenkins and Delbridge, 2014: 884). Rather the approach here is a psychoanalyticallyoriented critique of motivation (Arnaud, 2007: 1) in which it becomes possible to accommodate 
more complex conceptualizations of subjectivity. This approach underlines that whatever is constructed as a foreclosed and fixed self, happy or otherwise, is, from a psychoanalytic perspective, both alienated and an illusory covering-over of lack. This is not false in the sense that it can ever be corrected. Rather it is a structural dynamic and the aim here is to explore how this is played with by drawing on motivation discourse. I begin with a narrative by Jay, an account executive:

I get up in the morning in order to achieve my goals to become successful at my career, help out my clients, and to earn a living where I can live comfortable and do what I want to do. I enjoy interacting with a broad array of business owners from CEO's [to] other successful business owners... In general, I'm empathetic to clients and do everything I can to help...If you are ethical and polite to everyone you meet you will be successful and get everything you want out of your career or job.

We see here how Jay describes motivation in relation to goal achievement, success, career, helping others and earning a comfortable living. In so doing he can fix his identity and construct an imaginary self as someone who knows who he is and what he wants. This, in turn, allows him to obtain what he wants and become fulfilled in the process. Jay underlines how he enjoys interacting with clients and getting everything he wants out of his career. We also see how imaginary others are to validate this imaginary self, i.e. the clients he is helping. They stand in for a larger, more symbolic Other, whom he addresses when he refers to notions of success and career as that which is socially desirable to be motivated by. The latter is perhaps the "everyone" he is being ethical with and polite to, thereby fulfilling his desire to be recognized by the Other. I will return to the impossibility of doing so at a later point. For now, what is important to note is how motivation discourse provides narrators with resources to construct an imaginary self that is unified and complete. 
It is this sense of completion that narrators also draw on when discussing not only how much they love their work but also how meaningful they find it. Meaningfulness was mentioned repeatedly in the narratives. It seems to refer to something that work provides to narrators beyond an economic exchange as underlined previously (Ashar and Lane-Maher, 2004; Grant, 2007). But it also refers to a kind of complete enjoyment, or an enjoyment beyond what might come from making a living or helping others. For example, Tom, a physical therapist, explains:

I just love what I do. I like seeing people get better and I like being a part of that and I like the aspects of the job like the biomechanics and the anatomy. That stuff interests me and it makes work fun...I love all the aspects of my job whether I'm getting paid for it or not. Well, I gotta get paid for it to be able to pay my mortgage (laughs). I also like the fact that I am not chained down to a desk and that...I am a part of getting that person back to something that they love doing. It's a great feeling to know that you accomplished something and that you did everything you could for that person...I mean isn't that everyone's goal in this field, or any aspect of life, knowing that they help to better someone's life? It gives you a sense of accomplishment.

As before, Tom describes how much he loves his work and helping his clients. Unlike, Jay, however, Tom underlines this by downplaying the role of money. Indeed, the term money unsettles his imaginary self-constructions as he stresses that he would do his work regardless of pay. But then he laughs when alluding to what seems like a confession about him having to pay his mortgage. It is as if his love for and sense of meaning of his work is threatened by getting paid and he has to stress the latter as a necessity. For Tom, motivation is more than monetary and it is this "more" that is also critical to being validated by imaginary others, like his clients, and validating his imaginary self. Therefore, in Tom's narrative we already get a sense that the imaginary always runs up against symbolic limitations and what the Other, rather than imaginary others, may want. So while he and his clients may love that he loves what he does, the Other may also demand that he earn a living and pay his bills. 
This unsettling of the imaginary relative to the Other, and how it is impossible to articulate an authentic identity with authentic wants, is surfaced by the narrators around pay. For instance, Daren, a cabinet maker, underlines how his motivation goes beyond an economic exchange:

I like that I learn something every day. I feel useful. I get great satisfaction out of being productive and using my time productively. Whether or not I was getting paid for it, I would still have interesting projects going on that I would want to see finished. It's kind of a pride thing...It gives me a chance to use my creativity and see things through...I love dealing with customers, and building something that's going to be functional and appealing to the eye...I enjoy the whole process from beginning to finish, and actually finishing it and seeing their satisfaction when I'm done...I don't focus on the money...I focus on doing a good job, and then usually the rest of it takes care of itself.

Daren describes in detail how much he loves his work, especially the creative aspects, as well as helping his customers. He draws on the discourse of motivation to construct an imaginary self as someone who loves to learn and be useful, and who obtains what he wants from what he does. It is as if he is addressing an Other who suspects him of having money as a prime motivator and he has to assure us that he loves his work much more than that. Money seems to be addressed in the narratives as something that reduces work to being less meaningful or not offering sufficient discursive resources, the "more" referred to earlier, to construct a unified, imaginary self.

Therefore, while motivation discourse is drawn on in the narratives to construct imaginary selves, the narratives are also marked by various tensions that unsettle such constructions. We have seen some of this in the tensions articulated around money; and I now explore further tensions around the less enjoyable aspects of work. Specifically, I examine how narrators construct an imaginary self as someone who is motivated because they love what they do, but also face a number of difficulties and even hardships that might make what they do a 
great deal less lovable. For example, Anne, a ski instructor describes in detail how difficult the job that she loves can be for her:

I love dealing with people and teaching people, you know, not only am I imparting my own wisdom about skiing but I'm also sharing a beautiful environment with them and that really opens up a lot of windows for people. I really love watching them grow, you know, athletically and in the skill base but appreciating the outdoors as well. So, you know, in the strictest sense, my job is fantastic and it's the best that I could have. But when you add in all of the other elements, like management or a grumpy client, or, you know, grumpy coworkers, that makes it less perfect. It's a great job but there's a lot of little things that can make it great or miserable. I do things every day for free for my company, and one of the things is that I will talk to clients on the phone, not during business hours, and the company, it doesn't really care and I would do that because I love my job. The reality is that's why I do it, because I love what I am doing. I should mention you don't get paid a lot to do it and in the seven years I have done this, I have not gotten a raise, because it's not seen as important. The company doesn't provide health insurance. God forbid you get injured on the job! It is a dangerous job as well but it's my profession. I take it very seriously. I take classes. So you can see, it's a lot of hard work for not a lot of money. Bottom line, you have to love what you are doing, and you have to overlook all the day to day difficulties that you deal with, otherwise you will go crazy. If I hated it, I wouldn't be here.

As in prior narratives, Anne constructs an imaginary self as someone who knows who she is, for example, someone who knows how to deal with people and offer them growth opportunities by learning how to ski and enjoy nature. Again this self is defined by how it is validated by imaginary others, her clients for example, and finds fulfillment in doing so. She describes her job as "fantastic", inadvertently alluding to how it may literally fulfill her fantasy of suturing, or covering over, any lack by what she does. Yet, we also notice a number of tensions reiterating this very lack. The imaginary others she works with do not always validate that she is in a fantastic and loveable job, as they can be grumpy and uncaring. They do not seem to appreciate what she does sufficiently as they do not offer her more pay or even health insurance, and a great deal of what she does is unpaid.

While Anne repairs imaginary constructions of herself as fulfilled in a loveable job by saying that she overlooks such difficulties assuring us that she does not hate it, there is a sense 
that she does just that. Perhaps she does not hate it often, but hate is a possibility. Moreover, by

alluding to the potential for craziness, there is uncertainty about how much she does love her job.

There is uncertainty about how much her self can be said to be validated when she works so hard and is taking it so seriously, while her employer does not even pay her for all she does. The imaginary self constructed by Anne seems therefore rather precarious and in need of constant repair. One wonders why Anne hangs on to it and does not at least reflect on changing her situation. The latter is done in the next narrative, in which the narrator, Steve, a homicide detective, also describes the more difficult aspects of his work and, while he assures us that he still loves his work, he at least wonders about alternatives:

I truly can say that I love my job. Um, there is something very gratifying about, um, chasing after the worst of the worst criminals in our society. I feel like I am actually doing something to help society as a whole. I have been up against worst, um, the worst people in our world and it is extremely gratifying to be able to take those people out of society so that they cannot hurt anybody else. I feel really lucky that I do have a job that I look forward to going to work every day. It's a great job. On the flip side of that is the frustrating side of my job. It's those cases that I have where I know with $100 \%$ certainty who did it but I just cannot prove it. It drives me crazy. I think that in life you're always trying to do what's right, um, I believe I would always try to do what's right and what's honorable. I get a lot of gratification out of providing a family with knowing what happened and in numerous cases I have been able to do that and hugged mom after a conviction. Having mom crying in my arms thanking me that is probably the best part of my job. I think, I'm lucky in that I absolutely love going to work. Sometimes it's overwhelming and sometimes it's too much. There are a lot of other things I could be doing with my life. Um, I could conceivably be making a lot more money, have a lot more free time, but I wouldn't trade what I do to go do something else because I don't know that I would be happy. I think I do love this job.

Like Anne, Steve draws on motivation discourse to construct an imaginary self as someone who knows who he is and can obtain what he desires. He underlines how much he loves what he does and how grateful he is to do it. He is also validated by imaginary others whom he is gratified to help, like the mother who hugs him after a conviction. But we also see how he addresses himself to a social Other as he describes helping society and doing what is 
right. Importantly, his narrative is marked by a number of tensions that unsettle his imaginary construction as someone completed by what he does. The first is around how he has to deal with "the worst people in the world" and his work is often overwhelming. Not only having to deal with the "worst criminals", but also at times not being able to bring them to justice, are the things that make his work difficult and threaten his sanity. While, like Anne, Steve repairs the imaginary by confirming that he nonetheless loves his work, unlike Anne, he does wonder about alternatives. He mentions making more money and having more time as things that seem desirable, but then wonders if other jobs would make him happy. Even as he concludes that he loves his job, the phrase "I think" introduces uncertainty. By the end of the narrative his imaginary self seems more precarious and potentially more open to alternative constructions. We can see a similar dynamic in Susan's narrative. Susan is a librarian:

I have my friends who I work with and my bosses love me so it takes a lot of stress and worry of my shoulders. I kind of don't want to sound pathetic or anything, but it's almost like being accepted (laughs). You know, I really love my job too much. But it is work as well, and I'm strong and believe in the separation of work and leisure (laughs).

What comes through in Susan's narrative is not only how she draws on motivation discourse to construct an imaginary self, which is unsettled in various tensions, but also how this prompts further reflection. While Susan, like the other narrators, feels validated by imaginary others as someone who loves her work and is loved in return by her coworkers, there are a number of tensions that unsettle this. For instance, she phrases what might point to her as an imaginary self that is whole in feeling accepted by her coworkers as "it's almost like" and then laughs. She also prefaces this by saying that she does not want to sound "pathetic". All this underlines that the imaginary is unsettled by her lacking certainty over whether she is or is not as fulfilled as she claims. 
This uncertainty is further strengthened when she says that she loves her job too much pointing to both the Other's imperative to do so and the impossibility of being rendered whole and receiving as much as her love for her job makes her invest into it. When she concludes that she believes in separation of work and leisure and laughs again, we can hear not only the imaginary being unsettled but something more symbolic. The idea surfaces that it is important to appreciate the limitations of how much work can offer as a means for rendering the self complete and that separation is needed to keep something to oneself. As Susan says, after all work is also "work", underlining that it is also less than what imaginary constructions might promise.

\section{Motivation and the Symbolic}

We have seen so far how motivation discourse is drawn on to construct imaginary selves and how these may become unsettled in various tensions. In this section, I explore further what surfaced in the last narrative, namely that the symbolic not only unsettles the imaginary but offers an opportunity for taking a more symbolic stance in which the narrator can construct potentially transformative alternatives. Specifically, as we saw for Susan, such alternatives may lead to using the discursive resources offered by motivation discourse to reflect differently on the self, and wonder for instance, why one might love one's work too much, and, like in Steve's case, what other things one might want to do instead. For example, Adam, an operations manager, reflects on his motivation:

It makes me happy to see people leave and be like you are a part of their experience and they say we're doing a good job...It's not that I'm lazy it's just that in the niche of customer service there is nothing briefer than the valet experience. So if you just do it right, it's as short as it should ever be...we're just parking their car as a convenience but we're kissing their ass too (laughs). I don't want to do this forever, but I know that if something changes in my life I always have this to fall back on and that's huge. 
Like others, Adam constructs an imaginary self from motivation discourse as someone who is rendered happy by what he does and by imaginary others who validate that he does a good job. But this imaginary self is unsettled by a number of tensions that Adam seems to play with. He underlines how brief the service encounter is and how, when imaginary others are responding positively to him, they also do so because he is "kissing their ass". In this self-mocking style followed by laughter, he may acknowledge or amplify the imaginary nature of what he finds as making him happy at work and reflect on this further.

It is as if Adam's narrative now has a space for him to articulate how he feels about his job in a more open manner. He describes this job as something he can fall back on but not something he wants to do "forever". In this way, he draws on motivation discourse to take a different stance toward the imaginary qualities of his work and, unlike Anne who seems to keep hanging on to them despite hardships, Adam seems less stuck and can creatively reflect on what his work can and cannot do for him. It might not make him as happy as he wishes, but it might also offer some security as he explores other options. In this way, Adam does not cover over the lack that the unsettling of the imaginary points to but rather reiterates it in a way that offers him resources for alternative self-constructions. This also comes into view in a narrative by Lori, a pharmaceutical sales representative:

I've always been motivated by the desire to do a good job at whatever position I'm in. I've always been a go-getter, (laughs) and have always had the desire to excel in my job, both for my own personal satisfaction and for my employer...I feel like I do an alright job (laughs)... [and] I'm one of the lucky ones that enjoys their job...At the end of a work day I usually feel very satisfied. Some days are more stressful and hectic than others but that's common in most jobs...Losing my job a few years back was a wakeup call that taught me to be grateful and cherish the work I do have, and I feel like I'm a great asset to the company I work for. But when I meet the bonus quota, well on those days I'm extremely satisfied of course (laughs). But yeah...overall I'm happy the majority of my time in regards to my job. 
Lori draws on motivation discourse to construct an imaginary self as someone who enjoys her job and is gratified by her accomplishments. Imaginary others, like her employer, validate this self, by for example paying her a bonus and making her feel like an asset to the company. Unlike other narrators though, Lori introduces tensions into this construction when she refers to her motivation and desire to excel as applying to "whatever position I'm in". By underlining this, she introduces distance to her current work, in that her imaginary self is not necessarily tied to this particular job. Moreover, she refers to her work as "alright" and then laughs as if she is skeptical, like Adam, about how well she does what she does, and may not be stuck in the image of a fantastic job, like Anne.

Lori also underlines that the less enjoyable aspects of her work seem to be "common in most jobs" thereby taking a more symbolic stance toward the inevitable disappointments that accompany work as an imaginary project. She also plays with the idea of the meaningfulness of her work by pointing to how she gets personal satisfaction from it on most days and feels as an asset to her employer, but also enjoys the money she is paid. When she laughs about that, it seems different from when prior narrators laughed about money to defend against this as undermining the meaningfulness of their work. Lori, instead, seems to use it to play with the idea that it is important not to forget that work cannot be as meaningful as one might fantasize it to be. Perhaps this was a lesson she learned when she lost her job before, which she describes as a wakeup call, and why now she can be grateful to have a job and get what she wants from it. Such a symbolic stance may therefore point to a momentary attempt to traverse the fantasy that work can render the self whole and deliver the enjoyment promised (Hoedemaekers, 2009: 190). I explore this further in the next narrative by Valery, a media specialist:

Sometimes you're just having good days or bad days or somebody asks you to do something and you think that's just a ridiculous thing. But you just do it because it's part 
of your job and it's just so rare that usually just walking... down to the end of the driveway and back (laughs)...it's like, ok, that wasn't such a big deal...I think...you can make fairly positive work out of anything...it's kind of stepping back and looking at it and...figuring out what it is you need so that you can pull it all back together...I do really like what I do. And as long as I have to work, this is a pretty decent job.

What comes into view in Valery's narrative is how she constructs her imaginary self as more porous and detached from the inevitable lack she encounters in her work. She understands her imaginary reactions, such as when she might get upset that somebody makes "ridiculous" demands, but she laughs them off and steps back from them. In this stepping back and not trying to get imaginary fulfillment, she is able to construct herself in such a way as to get something fairly positive. Like Adam and Lori, Valery can see her job as structurally less satisfying and therefore take a more creative and empowering stance toward its frustrating aspects.

Valery is not in need of finding her job as lovable and fulfilling as we have seen other narrators do. Indeed, she can find her job to be "pretty decent" in view of the necessity to work ("as long as I have to work"). She can also find little bits to enjoy in her own way without having to be recognized by an Other, who might demand that she love her work or align herself with her employer's sanctioned self (Sonenshein et al., 2013: 564). Consequently, Valery's narrative has moments in which she is traversing the fantasy that work can keep her from experiencing lack. A similar dynamic comes into view in a narrative by Sara, a nurse practitioner:

I truly love what I do. I love being a part of people's lives. I get to see them in their best and in their worst...My job is very emotionally taxing and I have come to the point now, because I have been doing this for 16 years, I have to let it go. I have to separate... If I brought that home, that grief, I would be very unhappy...The big things that annoy me in my job is all the politics behind it...I work in a for profit...medical healthcare facility. Their bottom line is money...I feel like they don't treat their employees as human beings...Even though I love what I do and I love my patients, I don't love who I work for...I'm looking at another 5 to 7 years. Do I start over again? I have learned to cope. I mean, when I'm at work, I give $110 \%$...But I often wonder if I contribute to society. I think, I can do more...I could work for a nonprofit...Someday I hope to do more. 
Sara articulates much more strongly than Valery that she loves her work. But she also has a nuanced understanding of what aspects she might love versus those she might not. While at first, she constructs an imaginary self that is rendered complete by the work she loves and the imaginary others she loves to help, she also recognizes the fragility of this self. She understands the risks of over-investing into this imaginary self and describes learning to let go and separate. This articulates a more symbolic response not only to the emotionally-demanding nature of her work but also the particular political context of her employment relationship. Sara can separate her employer's focus on profits from her imaginary self as someone who is caring and has to continuously cover over the lack that is revealed by her employer's disrespect. Sara can both let go and separate it as a structural impediment that does not render her more or less fulfilled.

Sara can then use such moments of traversal to reflect on what she might want from work. She can separate the love she has for her patients from a lack of validation from her employer and thereby retain, like Valery, some enjoyment without feeling as if she should hold out for fantastical bliss, as Anne might do. This also means that Sara can draw on the discursive resources offered by motivation to be less rigid in her self-constructions and wonder, for instance, what else she might do or how she can position herself differently to the Other's desire. The Other's desire, in Sara's narrative, may be referenced when she talks about contributing to society. But even as she discusses this, she also describes hoping to do more, underlining that the Other's desire cannot be fulfilled (Fink, 2004: 119). Sara illustrates how neither the imaginary nor the Other ever cease to be articulated, but that one can take a unique position in doing so.

\section{Discussion}

The aim of the preceding analysis was to explore further how motivation can be understood in the context of identity work. As motivation researchers have turned away from 
instrumental views toward understanding work as a source of meaning and self-definition (Dutton et al., 2010: 265), motivation is conceived increasingly as a process by which individuals can articulate a preferred identity (Leonard et al., 1999: 973). As research has also underlined the importance of unconscious dynamics for understanding both identity and motivation, the aim was specifically to explore how the narrative construction of motivation can be understood in the context of the narrative construction of identity with an emphasis on how both are affected by struggles with unconscious desire and underlying lack (Arnaud, 2007). In analyzing narratives of individuals who describe what motivates them, the narration of motivation and identity emerges as a complex process. Narrators emphasize the ways in which work is meaningful to them beyond the achievement of instrumental ends and share how important work is relative to how they "story" (Dutton et al., 2010: 266) themselves.

From a psychoanalytic perspective, this process is elucidated further by examining how motivation furnishes discursive resources for the narrative construction of an imaginary self, which can define who it is and what it wants, and, importantly, be rendered complete in and through work. The meaning of work beyond economic exchanges emerges therefore as a way to cover over an underlying lack caused by the impossibility of knowing and fulfilling what is unconsciously desired. However, this lack continues to unsettle imaginary constructions in a number of ways. For example, there are tensions in many of the narratives around the meaning attached to money. Frequently, money is seen as that which threatens imaginary selves, as for example, employees who love their work, its creative and fun aspects, and the gratification that comes from helping others. Money is often positioned as that which would undermine such gratification and call into question whether individuals truly love their work or are truly who they say they are. Other aspects that unsettle imaginary self-constructions are the less enjoyable 
aspects of work. Demanding working conditions, low pay or uncaring management are some of the aspects described that threaten imaginary selves as individuals who love their work and can render themselves complete through it.

While some narrators remain attached to an imaginary order and seek to cover over any lack that so unsettles it, other narrators exhibit a more symbolic response (Vanheule et al., 2003: 335). They not only acknowledge the frustrating aspects of their work, but also that this is a structural rather than personal problem. Many of them describe not being attached to their current job, considering alternatives and trying to enjoy certain aspects of their work while knowing that any job can be difficult. They depersonalize the less gratifying aspects while taking an active role in shaping what they want to get out of work. That is, some narrators take a different position toward lack allowing them to move toward a working-through of the underlying fantasy that work can render the self unified and complete (Hoedemaekers, 2009: 190). There are moments in which they acknowledge that work is structurally unsatisfying (Arnaud and Vanheule, 2007: 363) and that, while it may seem at times that imaginary others can validate an imaginary self, in the end it is impossible to satisfy the desire of the symbolic Other (Lacan, 1977b: 214). In this vein, they not only articulate that work is difficult in many respects, they also let it go and separate their expectations about what they can enjoy about their work from the fantasy that it can be the perfect wish-fulfillment.

In this manner, they take a creative stance to articulate themselves and responsibility for the disappointments they encounter. From this perspective, it is not that there are all kinds of obstacles that prevent them from finding the meaning they attach to work, but rather that work requires finding a different stance to how meaningful one can expect it to be in the first place. This also enables some narrators to point out that money can be enjoyed as something that 
underlines that work is just work and yet does not mean that some aspects of it cannot be meaningful. However, meaning is not necessarily tied to being validated as someone who loves work completely, nor is it tied to denying its material aspects. Consequently, while an imaginary self can still be constructed by drawing on motivation discourse, this self is less fixed. It is more detached from the employer as an imaginary other. It also has space to accommodate not only the desire of the Other but the taking ownership of the impossibility of fulfilling it and enjoying the power and creativity this entails (Fink, 2004: 123).

As a result, motivation emerges as a much more complex process than simply allowing individuals to construct a preferred self that is aligned with organizational ideals (Sonenshein et al., 2013: 564). More imaginary responses to motivation are more likely to result in such an alignment, as the employer or coworkers serve as imaginary others who validate the employee not only as loving their work but also loving it in a such a way as to be productive for the organization. However, this alignment can also be unsettled as the imaginary is undermined by various tensions, and more symbolic responses become possible. As we have seen, several narrators, while enjoying their work, question whether they wish to remain in their current job or are less attached to it, as if jobs were interchangeable. But they have found a way to get what they want out of any job.

From this perspective, the idea that employers furnish discursive resources through motivation for identity work and thereby exert more control over employees seems to capture only one aspect of how motivation functions in the context of identity work. To the extent that individuals are tied more to imaginary responses to motivation, they would seem more attached to the fantasy that work can render them complete. Consequently, they might find promises made by employers to this end more seductive (Hoedemaekers, 2009: 190). However, to the extent that 
more symbolic responses are adopted, the power of such promises lessens, as it is this very fantasy that may be worked through in narrating motivation. Therefore, whether employees draw more on organizational rather than personal discursive resources for identity constructions (Sonenshein et al., 2013: 564) would seem to depend on the extent to which their responses are more imaginary or symbolic.

As imaginary and symbolic responses can coexist (Vanheule et al., 2003: 328), it is perhaps a kind of continuum rather than an all-or-nothing proposition. Some employees may lean toward the imaginary end and draw more on employer-provided resources, while others lean toward the symbolic and draw more on personal ones. This then also calls for a more nuanced understanding of what it means that motivation is a process whereby individuals are constructing a positive identity through work-related activities (Dutton et al., 2010: 267). Positive can refer to more imaginary responses whereby motivation discourse is drawn on to construct a whole, nonlacking self. But positive can also refer to more symbolic responses whereby it is used to construct a more porous imaginary self with space to reiterate underlying lack as a structural rather than personal condition and therefore to preserve some enjoyment rather than continue to hope for perfect bliss. In short, more complex and nuanced understandings of how motivation functions at the interstice of identity work emerge when examining this carefully in the context of struggles with unconscious desire.

\section{Conclusion}

The value of reading motivation narratives as both imaginary and symbolic responses is not that this reveals a deeper truth about what motivates individuals in organizations today. Rather the contribution the study hopes to make is to answer the call for more adequate theorizing on motivation (Locke and Latham, 2004; Steel and Koenig, 2006) by elucidating its 
tension-filled nature. Specifically, the study examines how the discourse of motivation is drawn on and played with in a rich and complex manner to construct identities along a continuum from imaginary to symbolic responses (Vanheule et al., 2003). This not only underlines how motivation can be explored as a socially-constructed linguistic phenomenon (Carlisle and Manning, 1994), but also how important it is to appreciate the role of unconscious desire and fundamental lack (Leather, 1983). As such, the study provides new avenues for extending and integrating prior research. It suggests that it is important to not only explore how individuals draw on discursive resources provided by organizations in an effort to motivate them and to construct a positive identity as a fixed and stable object. Instead, more attention needs to be paid to how such constructions are unsettled and not only look for narrative cohesion but also the many tensions and gaps that invariably mark them.

Such an approach would also allow for more complex conceptualizations of why motivation cannot be reduced to instrumental ends (Michaelson, 2005), and how its meaningfulness to individuals can be understood further. Specifically, ideas that individuals experience personal fulfilment in work (Parker and Chusmir, 1991) and see work as a place where a meaningful life can be realized (Ashar and Lane-Maher, 2004) should be explored in the context of imaginary self-constructions and the fantasy that the self can be rendered whole. It is important to examine such meanings relative to how they are unsettled and worked through and not confine research to examining whether they can or should be realized, or whether they empower or disempower individuals. From the perspective advanced here, the question is more how such meanings are articulated in specific narratives and whether or how they move individuals along the imaginary versus symbolic continuum. 
To the extent that they move individuals toward the imaginary end, they are more likely to be disempowering with regard to organizational control. They may be a force for selfexploitation in that individuals will work very hard to have their imaginary selves validated by others (Roberts, 2005). This, in turn, makes them more susceptible to be instrumentalized through motivation (Sievers, 1986) as dominant organizational discursive resources are drawn on to define the self and thus align it with managerial interests (Alvesson et al., 2008: 16). However, the inevitable failure of the imaginary not only denudes this project as an empty promise (Hoedemaekers, 2009: 194), it also offers opportunities for micro-resistance and "alternate subject positions from official ones" (Thomas and Davies, 2005: 690). In particular, the articulation of the structurally non-satisfying nature of work (Arnaud and Vanheule, 2007: 363) "turns the discursive condition of dominance into grounds of intervention" (Learmonth, 2009: 1901). Especially, because motivation discourse now pushes individuals to experience work as an encompassing journey in which to live and become who they wish to be (Ankli and Palliam, 2012: 9), it also drives into hyper-mode the experience of work as structurally non-satisfying.

The implication of this perspective for the study of motivation is to explore much more carefully how motivation is narrated in specific instances. That is, rather than focusing on which motivational theories seem to be most readily adopted or linked to discourses of performativity, it may be much more fruitful to explore which particular discourses of motivation are adopted in certain organizations by certain individuals. In so doing, the focus shifts from the seemingly endless quest for the "right" levers toward an understanding of how individuals experience motivation and, importantly, seek to articulate their desires in and through it. Motivation is an ongoing concern in organizations and, regardless of the particular approach adopted, fertile ground to explore how individuals encounter the structurally unsatisfying nature of work. Indeed, 
motivation may be the admission that it is so and therefore has to be engineered to appear otherwise (Sievers, 1986). But it is also fertile ground for empowerment and emancipation, especially, because it seems in constant need to be re-engineered. This offers ever new discursive resources that are mapped in creative ways onto struggles with fantasies and lack that can be attached to and let go of.

This suggests that motivation research can move from seeking to find what exactly people want from their work, managers or organizations, to exploring how the very lack at the heart of this search allows people to articulate a "sense of self" (Lacan, 1988b: 223). As a result, motivation research may be turned on its head from seeking to define and optimize the desire to work, toward an appreciation of work as a "central domain for the [failed] construction of the self" (Dutton et al., 2010: 266). This provides novel engagements with agency and motivation discourse as a resource for symbolic responses toward the necessarily empty promises made about work as a place of fulfillment. This perspective also moves motivation research toward not only providing additional avenues for understanding a "new era of work" (Steers, et al., 2004: 384) but also a more reflexive modernity.

It has been argued that we are experiencing an irreflexive modernity (Ekmann, 2015: 591) in which individuals are incapable of reflecting on consequences while being bamboozled by win-win fantasies of work that "veil the pain of exploitation" (Ekman, 2015). As motivation research provides spaces in which to listen to how individuals story themselves as they are pushed to make something out of their lives by working (Arnaud and Guinchard: 2008: 242), space is created for greater reflexivity. In this space work becomes an opportunity to experiment with new subject positions and alternative narrative structures that unsettle dominant discourses (Thomas and Davies, 2005: 701). Such a space requires little more than to listen more closely to 
how individuals in organizations talk (Learmonth, 2009), both within the officially-sanctioned organizational discourse on motivation as well as informally. This listening can be practiced with the help of researchers and facilitators or can be a collaborative effort in work groups building social resources (Dutton et al., 2010) as shared reflective, narrative practices.

Future research could explore this further by taking a Lacanian approach as illustrated in this study. This approach rests on seeking to make Lacanian ideas more accessible while also honoring their complexity and somewhat intentional open-endedness. To explore motivation from this perspective means to keep it alive as a Lacanian workspace in which the aim is not to close down and answer questions. Rather the aim is to open them up and leave them precisely as questions. That is, the goal of this kind of inquiry into motivation is to illuminate its complexities while highlighting questions and inspiring more inquiry and reflection. This might also offer novel avenues for engaging with motivation as a way to model an extended critical performativity (Spicer, Alvesson and Karreman, 2016).

One of the aspects of the latter is to look for opportunities for "micro-mobilization" (Spicer et al., 2016: 239) by engaging more with practitioners and their concerns while recognizing and developing alternatives in existing practices. As illustrated in this study, motivation is not only a widely used discourse in organizations, it is also relevant to employees and managers alike. Hence, there are opportunities for working with emancipatory potentialities in the narratives that are shared about it. Such potentialities require little more than to foreground the many contradictions that surround motivation. That is, rather than searching for the right levers or answers, simply allowing questions about motivation to resonate in ordinary conversations can turn motivation from a performative to a critically-performative project. 
The practical implication of this is that motivation can be supported as an emancipatory project by simply fueling the ongoing conversation about it in organizations (Locke et al., 2004). Lacanian analytic practice is built on the idea that the amplification (Lacan, 1988b: 241) of the imaginary and its failures is key to enabling more symbolic responses. As illustrated in the analysis provided here, exploring motivation in a Lacanian workspace therefore can be achieved by amplifying the tension-filled nature of motivation and, rather than showing how needs are met or goals accomplished, underlining how what is sought is so often not found. From this vantage point, the turn to identity in motivation research highlights perhaps the opposite of what is currently envisioned. Rather than to realize a desired self (Shamir, 1991), what may be most motivational about motivation discourse is to energize the process of articulating that there is nothing to realize, about either self or desire.

\section{References}

Alvesson, M., Ashcraft, K. L., Thomas, R. 2008. Identity matters: Reflections on the construction of identity scholarship in organization studies. Organization, 15(1): 5-28.

Alvesson, M., and Skoldberg, K. 2000. Reflexive Methodology. London: Sage.

Ankli, R.E. and Palliam, R. 2012. Enabling a motivated workforce: Exploring the sources of motivation. Development and Learning in Organizations, 26(2): 7-10.

Arnaud, G. 2007. The desire for work: Work motivation viewed from a psychoanalytic perspective. $13^{\text {th }}$ European Congress of Work and Organizational Psychology, Stockholm.

Arnaud, G. and Guinchard, R. 2008. A l'écoute du désir de travail. In R., Beaujolin, P., Louart and M. Parlier. Le Travail, un Défi pour la GRH. Lyon: ANACT, 236-252.

Arnaud, G. and Vanheule, S. 2007. The division of the subject and the organization: A Lacanian approach to subjectivity at work. Journal of Organizational Change Management, 20(3): 359369.

Ashar, H. and Lane-Maher, M. 2004. Success and spirituality in the new business paradigm. Journal of Management Inquiry, 13(3): 249-260. 
Barone, T. 2007. A return to the gold standard? Questioning the future of narrative construction as educational research. Qualitative Inquiry, 13(4): 454-470.

Barrick, M.R., Thurgood, G.R., Smith, T.A. and Courtright, S.H. 2015. Collective organizational engagement: Linking motivational antecedents, strategic implementation, and firm performance. Academy of Management Journal, 58(1): 111-135.

Benvenuto, B. and Kennedy, R. 1986. The works of Jacques Lacan. New York: St. Martin's Press.

Carlisle, Y.M. and Manning, D.J. 1994. The concept of ideology and work motivation. Organization Studies, 15(5): 683-703.

Cullen, D. 1997. Maslow, monkeys and motivation theory. Organization, 4(3): 355-373.

Dutton, J.E., Roberts, L.M. and Bednar, J. 2010. Pathways for positive identity construction at work: Four types of positive identity and the building of social resources. Academy of Management Review, 35(2): 265-293.

Ekman, S. 2015. Win-win imageries in a soap bubble world: Personhood and norms in extreme work. Organization, 22(4): 588-605.

Fink, B. 2004. Lacan to the letter. Minneapolis, MN: University of Minnesota Press.

Gabriel, Y. 1991. Turning facts into stories and stories into facts: A hermeneutic exploration of organizational folklore. Human Relations, 44(8): 857-875.

Gabriel, Y. 1995. The unmanaged organization: stories, fantasies and subjectivity. Organization Studies, (16): 477-502.

Glaser, B.G. 1978. Theoretical sensitivity. Advances in the methodology of grounded theory. Mill Valley, California: Sociology Press.

Grant, A.M. 2007. Relational job design and the motivation to make a prosocial difference. Academy of Management Review, 32(2): 393-417.

Hendry, P.M. 2007. The future of narrative. Qualitative Inquiry, 13(4): 487-498.

Hoedemaekers, C. 2009. Traversing the empty promise: Management, Subjectivity and the Other's desire. Journal of Organizational Change Management, 22(2): 181-201.

Hoedemaekers, C. and Keegan, A. 2010. Performance pinned down: Studying subjectivity and the language of performance. Organization Studies, 31(8): 1021-1044.

Holmes, R. 2014. Fresh kills: The spectacle of (de)composing data. Qualitative Inquiry, 20(6): 781-789. 
Jenkins, S. and Delbridge, R. 2014. In pursuit of happiness: A sociological examination of employee identifications amongst a 'happy' call-center workforce. Organization, 21(6): 867-887.

Johnson, R.E., Chang, C., Yang, L. 2010. Commitment and motivation at work: The relevance of employee identity and regulatory focus. Academy of Management Review, 35(2): 226-245.

Kanfer, R. and Ackerman, P.L. 2004. Aging, adult development, and work motivation. Academy of Management Review, 29(3): 440-458.

Kehr, H.M. 2004. Integrating implicit motives, explicit motives, and perceived abilities: The compensatory model of work motivation and volition. Academy of Management Review, 29(3): 479-499.

Lacan, J. 1977a. Ecrits. New York: Norton.

Lacan, J. 1977b. The four fundamental concepts of psychoanalysis. London: Hoghart Press.

Lacan, J. 1988a. The seminar of Jacques Lacan, Book I: Freud's papers on technique 1953-1954. New York: Norton.

Lacan, J. 1988b. The seminar of Jacques Lacan, Book II: The ego in Freud's theory and in the technique of psychoanalysis 1954-1955. New York: Norton.

Lacan, J. 1991. Le seminaire de Jacques Lacan 1969-1970, Livre XVII: L'envers de la psychanalyse. Paris: Editions Du Seuil.

Lacan, J. 2001. Autres Ecrits. Paris: Editions Du Seuil.

Leather, P. 1983. Desire: A structural model of motivation. Human Relations, 36(2): 109-122.

Learmonth, M. 2009. 'Girls' working together without 'teams': How to avoid the colonization of management language. Human Relations, 62(12): 1887-1906.

Leonard, N.H., Beauvais, L.L. and Scholl, R.W. 1999. Work motivation: The incorporation of self-concept-based processes. Human Relations, 52(8): 969-998.

Locke, E.A. and Latham, G.P. 2004. What should we do about motivation theory? Six recommendations for the twenty-first century. Academy of Management Review, 29(3): 388403.

Michaelson, C. 2005. Meaningful motivation for work motivation theory. Academy of Management Review, 30(2): 235-238.

Ollerenshaw, J. and Creswell, J.W. 2002. Narrative research: A comparison of two restorying data analysis approaches. Qualitative Inquiry, 8(3): 329-347. 
Parker, I. 2005. Lacanian discourse analysis in psychology. Theory \& Psychology, 15(2): 163 182.

Parker, I. 2010. Psychosocial studies: Lacanian discourse analysis negotiating interview text. Psychoanalysis, Culture \& Society, 15(2): 156-172.

Parker, B. and Chusmir, L.H. 1991. Motivation needs and their relationship to life success. Human Relations, 44(12): 1301-1312.

Ragland, E. 1996. An overview of the real, with examples from seminar I. In Feldstein, R., Fink, B., and Jaanus, M. (Eds.) Reading seminars I and II: Lacan's return to Freud. Albany, NY: State University of New York: 192-211.

Roberts, J. 2005. The power of the 'imaginary' in disciplinary processes. Organization, 12(5): 621-645.

Saville Young, L. 2014. Becoming other to oneself: Misreading the researcher through Lacanian discourse analysis. In Parker, I. and Pavon-Cuellar, D. (Eds.). Lacan, discourse, event: New psychoanalytic approaches to textual indeterminacy. London: Routledge: 223-234.

Shamir, B. 1991. Meaning, self and motivation in organizations. Organization Studies, 12(3): 405-424.

Sermijn, J., Devlieger, P. and Loots, G. 2008. The narrative construction of the self: Selfhood as a rhizomatic story. Qualitative Inquiry, 14(4): 632-650.

Sievers, B. 1986. Beyond the surrogate of motivation. Organization Studies, 7(4): 335-351.

Sonenshein, S., Dutton, J.E., Grant, A. M., Spreitzer, G. M. and Sutcliffe, K.M. 2013. Growing at work: Employees' interpretations of progressive self-change in organizations. Organization Science, 24(2): 552-570.

Spicer, A., Alvesson, M. and Karreman, D. 2016. Extending critical performativity. Human Relations, 69(2): 225-249.

Spreitzer, G., Sutcliffe, K., Dutton, J., Sonenshein, S., Grant, A. 2005. A socially embedded model of thriving at work. Organization Science, 16(5): 537-549.

Stavrakakis, Y. 2008. Subjectivity and organized other: Between symbolic authority and fantasmatic enjoyment. Organization Studies, 29(7): 1037-1059.

Steel, P. and Koenig, C.J. 2006. Integrating theories of motivation. Academy of Management Review, 31(4): 889-913.

Steers, R.M., Mowday, R.T. and Shapiro, D.L. 2004. The future of work motivation theory. Academy of Management Review, 29(3): 379-387. 
Sullivan, J.J. 1988. Three roles of language in motivation theory. Academy of Management Review, 13(1): 104-115.

Thomas, R. and Davies, A. 2005. Theorizing the micro-politics of resistance: New public management and managerial identities in the UK public services. Organization Studies, 26(5): 683-706.

Tuck, E. and Yang, K.W. 2014. Unbecoming claims: Pedagogies of refusal in qualitative research. Qualitative Inquiry, 20(6): 811-818.

Vanheule, S., Lievrouw, A. and Verhaeghe, P. 2003. Burnout and intersubjectivity: A psychoanalytical study from a Lacanian perspective. Human Relations, 56(3): 321-338. 